\title{
$O$ ensino de geometria na construção de maquetes
}

\author{
Grêicy S. Agostiniaki Daniela R. Teza \\ Universidade Tecnológica Federal do Paraná - Curso de Licenciatura em Matemática \\ 80230-901, Curitiba, PR \\ E-mail: gsagostiniaki@gmail.com, daniela_teza@hotmail.com \\ Vitor J. Petry \\ Universidade Tecnológica Federal do Paraná - Departamento Acadêmico de Matemática \\ 80230-901,Campus Curitiba-PR \\ E-mail: vpetry@utfpr.edu.br
}

\section{RESUMO}

Nas discussões atuais a cerca do ensino de matemática, muito se fala em aliar teoria e prática. Esta recomendação surge como uma tentativa de melhoria do ensino nesta área, que à tempos recebe críticas por causa de seus aspectos formais que, na visão de muitos, são exacerbadamente explorados e tornam a disciplina de matemática desestimulante para muitos alunos. Buscando alternativas para contribuir com a melhoria do ensino, desenvolvemos o projeto intitulado "Projeto Maquete". A finalidade do projeto era aproveitar a motivação e a visualização concreta proporcionada pela construção de uma maquete, para trabalhar conceitos e resultados de matemática elementar, especialmente questões relacionadas com geometria.

O Projeto Maquete foi desenvolvido como parte das atividades de um grupo de bolsistas do PIBID ${ }^{1}$. Com o presente trabalho, pretendemos socializar a experiência que obtivemos ao trabalhar os conceitos de geometria presentes na construção de uma maquete a fim de subsidiar professores que desejam trabalhar este conteúdo de maneira mais atraente, tendo, porém, sempre em mente a necessidade de formalizar também a teoria envolvida. Serão descritas também algumas experiências vivenciadas durante a execução do projeto além da exposição de alguns dos resultados.

O projeto foi executado, no Colégio Estadual Júlia Wanderley, na cidade de Curitiba, PR com trinta alunos de sétimos e oitavos anos do ensino fundamental. Os encontros, quinzenais, ocorreram aos sábados pela manhã, durante um semestre letivo e por se tratar de um horário extraclasse, a participação dos alunos no projeto se deu por adesão. Diversas atividades desenvolvidas, como atividades teóricas, oficinas, atividades no laboratório de informática e a construção das maquetes. As atividades teóricas que compreendiam conteúdos básicos, necessários para a construção de uma maquete, tais como noções de espaço e forma, escala, ângulos, simetria, congruências, paralelismo, perpendicularismo, perímetro e área. Estas atividades foram desenvolvidas ao longo da execução do projeto, integradas às demais atividades.

Os alunos tiveram a oportunidade de participar de oficinas de origami e de desenho geométrico promovidas na universidade, com auxílio de professores o Curso de Licenciatura em Matemática. A oficina de origami teve como objetivo mostrar aos alunos, por meio de dobraduras, os conteúdos básicos trabalhados nas atividades teóricas e alguns outros conceitos presentes na geometria das dobraduras. A oficina de desenho geométrico, além de reforçar os conteúdos básicos teve como principal finalidade fornecer aos alunos as ferramentas necessárias para construção da planta baixa da maquete que seria realizada posteriormente.

$\mathrm{Na}$ etapa seguinte, os alunos realizaram a construção da planta baixa, para a qual, eles forma divididos em quatro equipes. Cada equipe selecionou uma planta e iniciaram a construção utilizando as técnicas de desenho geométrico. Na sequência os alunos puderam utilizar os computadores do Laboratório de Informática do Departamento de Matemática da UTFPR. No

1 Programa Institucional de Bolsa de Iniciação à Docência. Subprojeto de Matemática da Universidade Tecnológica Federal do Paraná - UTFPR, Campus Curitiba, coordenado pelo Prof. Dr. Vitor José Petry e sob a supervisão da Prof. Karine dos Santos Biazi na Escola de aplicação. 
laboratório utilizamos o Autodesk Homestyler, que é um software gratuito, para projetos em 3D, que permite a construção online da planta baixa e a partir dela visualizar o projeto finalizado. Na sequência das atividades, partiu-se para a confecção efetiva das maquetes, atentando para a correta transposição da planta, sendo fiel a escala adotada. Para concluir foram construídos os telhados, novamente com a discussão de conceitos geométricos envolvidos, e cada equipe ornamentou a maquete a sua maneira.

Durante o desenvolvimento do projeto, tivemos o apoio e a mobilização de diversos professores e da Escola, e no encerramento os projetos foram socializados para a comunidade escolar. Apesar do envolvimento de alunos e professores da escola, algumas dificuldades surgiram durante o desenvolvimento das atividades, principalmente, por se tratar de um projeto de modelagem matemática, o que possibilita o surgimento de situações que não foram ponderadas durante o planejamento, porém, não menos importantes de serem trabalhadas. Elencamos na sequência algumas situações surgidas e que consideramos relevantes.

O projeto proporciona ao professor uma aproximação maior com alunos de modo a perceber de maneira mais sensível as dificuldades e o potencial dos alunos, o que leva o professor a uma reflexão mais honesta sobre a qualidade do ensino/aprendizado. Por outro lado, os alunos que apresentam maior dificuldade com o ensino tradicional, têm a oportunidade de serem avaliados de forma mais subjetiva.

Apesar dos benefícios no campo do ensino/aprendizagem, pudemos notar que o professor esbarra em questões burocráticas que envolvem a aquisição de materiais, alguns materiais podem ser trazidos pelos próprios alunos, mas o essencial deve ser fornecido pela escola. Tivemos o privilégio de utilizar um laboratório de informática bem equipado, gentilmente cedido pela universidade, mas sabemos que nem todas as escolas possuem laboratório de informática, e as que o possuem, nem sempre o têm em bom funcionamento. Também se deve levar em conta que as atividades práticas demandam espaço para que as equipes possam trabalhar mais livremente e talvez até disjuntas. Por isso optamos em realizar as atividades aos sábados, foi a nossa solução para a questão de espaço.

Durante a aplicação do projeto, observamos um comportamento colaborativo e comprometido por parte dos alunos participantes, de forma que não registramos nenhum evento significativo que pudesse ser considerado um problema de descontrole ou falta de comportamento adequado dos alunos. Observou-se da parte dos alunos uma responsabilidade em desenvolver cada uma das atividades propostas e a vontade/necessidade de compreender a matemática envolvida. Esta situação ficou evidente também na socialização dos resultados, no dia do encerramento. Os alunos compreenderam que cada etapa de aprendizagem dentro do projeto tinha uma influência direta no projeto final. $\mathrm{O}$ projeto estimulou os alunos a fazer a matemática escolar com responsabilidade.

Palavras-chave: ensino geometria, modelagem na educação básica.

\section{Referências}

[1] Bassanezi, Rodney Carlos. Ensino-aprendizagem com modelagem matemática: uma nova estratégia. 3. ed. São Paulo: Contexto, c2006. 389 p.

[2] Brasil. Ministério da Educação. Secretaria de Educação Fundamental. Parâmetros Curriculares Nacionais: Matemática. ( $3^{\circ}$ e $4^{\circ}$ ciclos do ensino fundamental). Brasília: MEC, 1998

[3] E. Wagner, Construções Geométricas. SBM - Coleção do professor de matemática. $6^{\text {a }}$ ed. 2007.

[4] Y. Chevallard et. al., Estudar matemáticas. O elo perdido entre o ensino e o aprendizagem (Trad. de Daisy Vaz de Moraes). Artmed. 2001. 